\title{
A mass bleaching event involving clionaid sponges
}
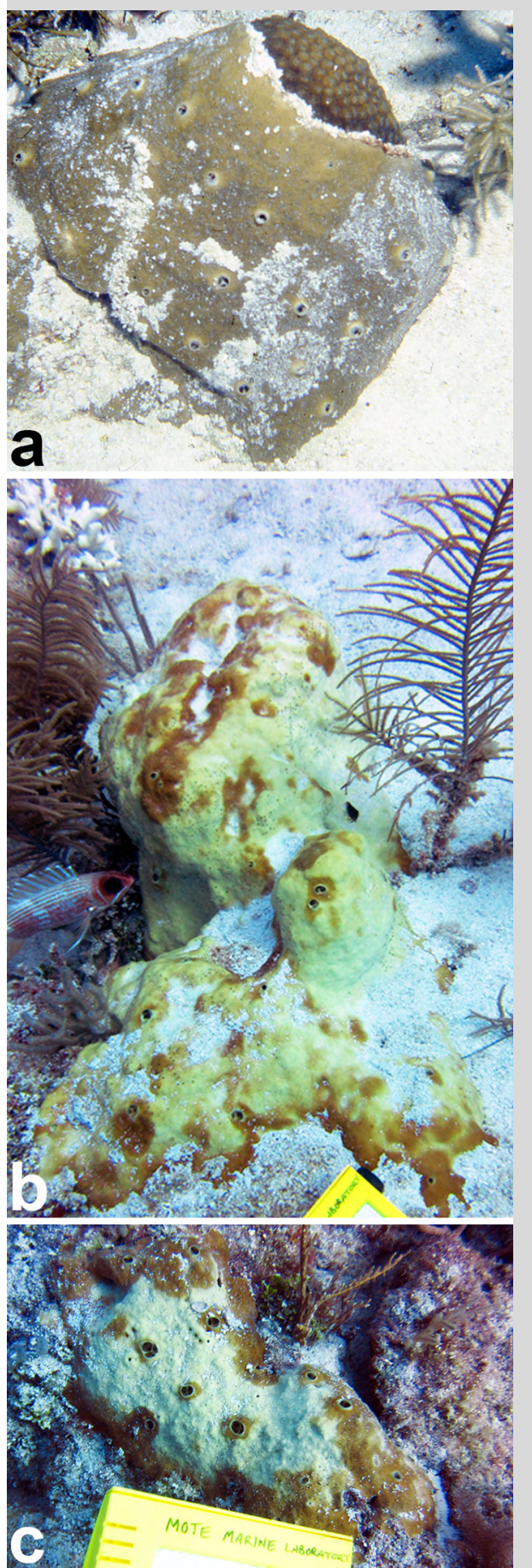

Fig. 1 a Non-bleached (typical) Cliona varians forma incrustans growing over a Montastrea cavernosa colony (photograph by M. Hill). b, c Representative examples of bleached $C$. varians observed in October 2015 (photographs by C. Walter)
The Caribbean sponge Cliona varians forma incrustans harbors dense intracellular populations of Clade G Symbiodinium (Fig. 1a; Hill 1996). Symbioses between bioeroding clionaids and Symbiodinium spp. are typically unaffected by the environmental stressors that induce bleaching in corals (e.g., Schönberg and Suwa 2007). However, in October 2015 we observed widespread $C$. varians bleaching on reefs at $12-15 \mathrm{~m}$ in the lower Florida Keys (Fig. 1b, c; Electronic Supplementary Material Fig. S1). The cause of sponge bleaching appears related to water temperature. Average daily temperatures $>31{ }^{\circ} \mathrm{C}$ persisted for 10 days (5-15 September) with a maximum temperature $>32{ }^{\circ} \mathrm{C}$. Sponge bleaching became obvious around the first week of October. While bleaching in $C$. varians can be induced artificially (Hill and Wilcox 1998), this appears to be the first report of a mass bleaching event involving clionaid sponges under natural conditions. Disrupting the symbiosis may have consequences for reef health if sponge filtration efficiency is impaired, rates of bioerosion are compromised, or non-native symbionts establish residency. Interestingly, the shallow-water C. varians forma varians did not bleach at an adjacent inshore site despite experiencing 17 days with average temperatures $>33{ }^{\circ} \mathrm{C}$ and maximum temperatures $>41{ }^{\circ} \mathrm{C}$. While differential bleaching susceptibilities may exist among individuals and clionaid species, the observations reported here indicate that sponge-Symbiodinium symbioses can be destabilized by environmental stressors in a manner similar to corals. These observations are troubling given increasing intensity and frequency of warming events, the abundance of sponges in reef ecosystems, and the essential ecological role they play in coral reef productivity.

\section{References}

Hill MS (1996) Symbiotic zooxanthellae enhance boring and growth rates of the tropical sponge Anthosigmella varians forma varians. Mar Biol 125:649-654

Hill MS, Wilcox TM (1998) Unusual mode of symbiont acquisition after bleaching in the tropical sponge Anthosigmella varians: acquisition of different zooxanthellae strains? Symbiosis 25:279-289

Schönberg CHL, Suwa R (2007) Why bioeroding sponges may be better hosts for symbiotic dinoflagellates than many corals. In: Custódio MR, Lôbo-Hajdu G, Hajdu E, Muricy G (eds) Porifera research: biodiversity, innovation and sustainability. Museu Nacional, Rio de Janeiro, pp 569-580

Electronic supplementary material The online version of this article (doi:10.1007/ s00338-016-1402-7) contains supplementary material, which is available to authorized users.

\section{Hill (ه)}

Department of Biology, University of Richmond, Richmond, VA 23173, USA

e-mail: mhill2@richmond.edu

C. Walter $\cdot$ E. Bartels

Mote Marine Laboratory, Summerland Key, FL 33042, USA 